SCHOLARS: Journal of Arts \& Humanities

Volume 3, No. 1, February 2021, pp. 34-46

[Peer-Reviewed, Open Access, Indexed in NepJOL]

Print ISSN: 2773-7829; e-ISSN: 2773-7837

DOI: https://doi.org/10.3126/sjah.v3i1.35357
Central Department of English

Tribhuvan University

Kirtipur, Kathmandu, Nepal

www.cdetu.edu.np/ejournal/

Theoretical/Critical Essay Article

\title{
Social Change and Modernity: Identity Crisis of the Bonda Tribe in Pratibha Ray's The Primal Land
}

\author{
S. Chitra, PhD \\ Postgraduate Department of English \\ Sangay Tenzin \\ Ministry of Education, Bhutan
}

Yonphula Centenary College, Royal University of Bhutan, Bhutan

Corresponding Author: S. Chitra, Email: schitra.ycc@rub.edu.bt

Copyright 2021 (C) Author/s and the Publisher

\begin{abstract}
Pratibha Ray's anthropological novel The Primal Land (1993) documents the history of India's endangered Bonda tribe dwelling in the secluded mountains of Koraput, Odisha. Not free from the interferences of the outside world, the Bondas face the threat of losing their tribal identity. This complicated position and their struggle between existence and identity, an intersubjective reality, was triggered by oppressive internal and external surroundings due to the pressures of modernity. The discussion focuses on their inherent cultural practices causingconstant internal feuds and the government's intrusion with development plans leading to exploitation, cultural dilution, and socioethnic tension. Thus the paper decodes the difficulties of the Bondas and concludes that their existence cannot be ensured without the loss of primal identity.
\end{abstract}

Keywords: Bonda tribe, identity, cultural practices, internal feud, modern development, socio-ethnic tension

\section{Introduction}

Tribes are generally described as social groups with their own language, territory, culture, and customs. They are perceived as primitive, illiterate, simple, and backward belonging to communities positioned outside a civilization. In the Indian context, tribal and indigenous peoples are those whose, "social, cultural and economic conditions distinguish them from other sections of the national society, and whose status is regulated wholly or partially by their own customs or traditions or by special laws or regulations" (Pati 21). For them, the land was not merely a source of livelihood rather a representation of their cultural identity and existence. In the name of development, the tribal communities in the post-colonial India have been alienated not only from the development processes but even from their own dwellings. With modernization, more lands in the tribal regions are being appropriated and the tribes are displaced and exploited and their culture, distorted. As the mainstream development processes tended 
to create social spaces of inequality, the tribal communities faced marginalisation virtually in every sphere of social life. Due to this reason, their long-standing social position, which is 'self-representation', has become a question mark. In fact, the loss of land and socio-cultural change has further jeopardized their identity.

The history of writing about the tribes in India dates back to the beginning of the nineteenth century. The publication of an anthropological journal, Man in India (1921), and the establishment of Anthropological Survey of India (1954), led to the organized study of the various tribal communities of India whereby the culture of tribal orality in the form of folklores, legends, and other literature for the purposes of references and studies were recorded (Sengupta). Moreover, the post-independence era saw the birth of novel writing on tribal subjects in almost all major Indian languages, which represented the tribal lives in a fictional framework by different writers. One such significant Odiya writer was Ray who took to writing inspired by her father's encouragement in her childhood, followed by Gopinath Mohanty's immense contribution to Odishan literature, and in her later years by Tolstoy's humane thematic concerns. Her writings were published since the 1970s beginning with Barsa Basanta Baisakha (The Rain Spring Summer, 1974), which became the bestseller. By mid-eighties, Ray was already recognized as a forefront writer in Odisha. Her anthropological novel The Primal Land (1993) is fictionalized based on her research experiences about the aboriginal Bonda tribe of Odisha. Before writing this novel, she did her post-doctoral research in the 1970s on Tribalism and Criminology of Bonda Highlander, which unravelled the unearthly folk morals and socio-ritual lifestyle of the Bonda tribe in the secluded Bonda hills of south-west Odisha.

\section{The Bonda Tribe and the Politics of Development}

It has been theorized by many historians that the Aryan invaders who considered themselves as a pure race, used their military might to push the tribals into the internal hilly and forest dwellings, and since then they have been leading a life of isolation. Odisha is one of the states with the largest number of tribes with as many as sixty two tribal ethnic groups, which constitute around the nine million total populations that makes 22.1 percent of the total population of the state (Census of India 2011). According to anthropologists, the Bonda tribes of Odisha are associates of a group of Austroasiatic tribes, who at some time in the past migrated and settled in an area of about one hundred and thirty square kilometres in the desolate hills of Jeypore in Malkangiri district near the intersection of the three states: Odisha, Chhattisgarh, and Andhra Pradesh. The area where the Bondas live in thirty two villages in Khairaput Block, in the Bonda hills at the elevation of three thousand feet above the sea level consisting of Mudulipada, Kadamguda, Podaghat, Andrahall, Rasabeda and Badadural is known as the Bonda Ghati (Ray vi). Existing in two different divisions, the Upper Bondas remain isolated from the mainstream Indian society with a population of six thousand seven hundred whereas the Lower Bondas, with an approximate population of twelve thousand two hundred and thirty one, has come closer to the outside world in opposition to the Upper Bondas (Census of India 2011). Ever since the government has tried to bring the Bonda tribe into the mainstream by setting up the Bonda Development Agency (BDA) in 1977, the outside influences have given the Bondas new gods, new languages, and new knowledge, resulting in their assimilation with the mainstream Odisha society despite the 
fact that the tribe is governed by unique cultural norms and belief system in terms of marriage. The novel, an ethnographic narrative delineates a close-knit tribal community located in a factual setting and landscapes with fictitious plot and characters, governed by kinship bonds and unique cultural patterns. Ray's work represents her sense of social responsibility and commitment to the socio-political and economic conditions of the tribal as well as the agrarian communities and cultures of her state.

The book not only portrays the themes of exploitation by the intruders and the tribal struggle for existence but it also deals with the internal problems of goti (bondedlabour) through the sahukars and other socio-economic problems faced by the tribes. The paper analyses the complexity of their inherent cultural practices such as the Bonda marriage system and the Bonda's financial dependence on sahukar, the moneylender as signs of internal disorder that endanger the survival of the tribe. At the same time, the exploitation of the tribal community by external forces such as the Dombs and gulangbabus, the government officials threaten the position of the tribe. Owing to the oppressive internal and external surroundings, the tribes are torn between existence and identity. Moreover, the government's interference into their community with the socalled development plans leads to exploitation, cultural dilution, and socio-ethnic tension which further complicates their position and a as result, the Bonda tribe's indigenous identity becomes a 'problem in question'. Therefore, this paper aims to explore the intersubjective realities in relation to the precarious position of the Bondas whose dilemma is whether to exist with intact tribal identity or adapt and march with modern ways. For this purpose, the study focuses on the causal effect of the Bonda tribes' inherent cultural practices and the politics of development from the outside world and analyses the eventual impacts that endanger their existence and identity.

Literatures written on tribal subjects throw light on the array of cultural diversity, particularly the endemic and endangered socio-cultural aspects of the indigenous tribes. When ethnography is written in the form of a novel, it not only represents people and their culture but it also helps connect their past with the present to anticipate their future in symbolic ways (Ralte). Bikram Nanda's Contours of Continuity and Change: The Story of the Bonda Highlanders (1994) portrays the predicament and the state of Bonda tribes with the claim that until the 1970s, Bondas led a self-sustained life by growing food for local consumption, that their agriculture was an evidence to optimal biodiversity, and the environment of rough terrain safeguarded and insulated them from the outside world. However, all this is practically lost today due to the politics of Bonda tribal development from the outside world. After his visit to the Bondaland, Verrier Elwin described their uniqueness in traditions and earthly lifestyles in his book Bondo Highlander (1950) whereby he notes that their traditional tribal beliefs are gradually blending with Hinduism though the Bonda tribes are not the distinctive Hindu tribe of India. At the core of their tribal belief is the 'Supreme Being' called Mahaprabhu, the creator of the world, who is neither omniscient nor omnipotent, but the one who creates through transformation.

Fascinatingly, the Bonda oral tradition contains a variety of myths on the creation that varies considerably from one another. From the clean-shaven heads of the women to the vengeful curse of the Gurangpoi, their life is governed by mythical beliefs which offer an understanding of the multiplicity of cultural traditions. The Bondas have lived in the remote mountainous area for ages, hidden from the curious gaze of the 
civilised world and have maintained their customs for generations until the influences of civilization came marching into their territory and decided to change them. As the outside visitors frequented the Bonda regions, the contact and inquisitiveness have had its devastating effects on the culture, tradition, wisdom, and low-carbon footprint lifestyle of the Bonda community. Claiming the tribe as not uncivilized, there is a tone of concern in the words of Verrier Elwin, who states, "Let us teach them that their (tribal) own culture, their own arts are the precious things, that we respect and need. When they feel that they can make a contribution to their country, they will feel part of it” (75). True to this statement, the unique aspect of their language, studied by Anderson and Harrison (2014) in the book chapter titled Remo (Bonda) affirms the southern part of Odisha as the geographical locale of the Bonda settlement inhabited by several thousand Remo language speakers. Statistically, it has been observed that, although the total number of the Plains Remo (Lower Bondas) increased from two thousand five hundred and sixty five to four thousand seven hundred and sixty four between 1941and 1971, the total number of speakers of the Remo language did not grow (Anderson 63). Nevertheless, without limiting itself to the statistical projection of the Bonda language speakers, the chapter provides a detailed account of the Bonda community as a ferocious tribal group. Moreover, the narrative details of The Primal Land also confirms the fact that the tribal community contains numerous complexities in its inherent cultural practices of marriage, myths and belief systems with biased laws which endanger their existence as a distinct group along with the influx of outside influences which is the focal idea of the paper.

\section{The Primal Land: An Anthropological Analysis Structure of the Narrative}

Ray's The Primal Land divided into thirty chapters with three-hundred pages, presents the story of tribal closeness to 'mother' nature and the origin of the Bonda land. The first eighty pages narrate the Bonda tribe's close affinity to their myths and legends that originate from the surrounding natural elements, which govern their everyday lives. Predominantly narrated from the point-of-view of 'ancient' Soma Muduli, who has become a dokra (old) and is revered as the leader of the twelve Bonda villages, the novel brings forth the issues of how the Bondas are subjected to exploitation ever since the outsiders' intrusion into their country in the 1970s and 1980s. In the later part of the novel, the novelist portrays how the influences have disintegrated the traditional beliefs of the Bonda tribe, wherein the older members like Soma Muduli watch with helplessness and defeat with the much-feared question suspended in their minds, 'Can the Bondas manage to keep their culture alive?' The novel shows that in the postindependence era, the tribes are highly exploited by the corrupt government officials along with the insiders such as the sahukars (moneylenders) and the Dombs, a mixedtribe from outside who had settled in the Bonda country.

In the introduction to the novel, Bikram K Das, the translator, rightly states that this novel "could well serve as their obituary" (Ray viii) as the Bondas are being assailed by dominant cultures that leave them on the threshold of extinction. Strikingly, both Ray, the author and Das, the translator have drawn a parallel concern while presenting a distorted future for the Bondas. Much concerned about a culture that is on the verge of disappearance and wedged in the mesh of dominant cultural strata, both Das and Ray have felt that documentation of the Bonda life in writing is the only means to preserve 
their identity. Having spent some time in the Bonda habitat while doing her postdoctoral research work, Ray has gained first-hand knowledge in direct contact with the Bondas and the study gave rise to her novel. With a blend of ethnographic account and fictitious characters, the narrative seems to be a fictionalized reconstruction of the Bonda tribe dwelling in the inaccessible region of Malkangiri, Odisha.

\section{Unusual Cultural Practices of the Bonda Tribe}

The narrative revolving around the uncommon cultural practices of the Bonda tribe that makes the reader question whether their beliefs secure their existence or problematize it.Though the Bondas' unique socio-cultural identity provides them with a sense of security and well-being, their existence is threatened by the inherent cultural practices, which are governed by strange myths and belief systems, resulting in constant internal feuds not only among the Bondas of the mountains but also with the Bondas of the plains. On the other hand, the government's intrusion into their land with development plans, rather than improving their lives lead to exploitation, cultural dilution, and socio-ethnic tension. Not free from the interferences of the outside world, the tribes face the threat of losing their tribal identity for the sake of sheer existence in line with the demands of the mainstream society. According to Sharma, "identity relies in part on the various inter-subjective meanings through which a group of people perceive the self and the other” (14). Marriage is one of the cultural identities of any tribal community. The strange marriage system of the Bondas is a curious subject wherein the wives are ten years older than the husbands during the marriage. A Bonda's development to a marriageable age is shown through the character and life of Soma Muduli, who was merely eight years old when he wedded Sombari. The narration of Soma Muduli's life contains elements of traditional Bonda courting that require spending money, especially on ornaments to please women. The young man's father is required to spend not only for the bride-price but also to give a lavish meal for the community and to build a new dia (home) for the newly married.

The dhangras were welcomed with the roasted flesh of mountain rats, dried fish, puffed rice and other delicacies. The dhangras, on their part, brought gifts from the haat, the open-air market: brass rings, sweet jalebis fried in oil, savoury rice fried and spiced or even mahula liquor. A selani had to be wooed with gifts. (23) It was the sahukar who "had helped Soma Muduli to get married: he has provided money to pay the bride's - price, to feast his kinsmen - though his father's lands and trees had passed into the sahukar's possession" (42-43). Since the woman, who is usually in twenties is married to an eight or ten year old boy, the wife becomes the caregiver for the boy while waiting for him to mature. Upon attaining his maturity, a Bonda man is considered independent and all decisions in life are made by him at free will. However, a Bonda woman's role does not change. The novelist has connected this strange practice to the legends and myths of the Bondas, which are passed from generation to generation.

To know people and their culture, it is essential to understand their legends and folklores through the tradition of orality which links their past with the present. However, Roland Barthes in Mythologies uses the term 'myth' as indicative of any made up, 'illusory thing', the 'false representations', and 'invalid beliefs' prevalent in the community, which we accept as 'natural' (Leak 1994). In the tribal communities, myths are important because their beliefs are generally not influenced by social and historical 
changes. Since their myths are clear to them, they depend on them to guide their social sphere and knowledge. The legend of Budei Mahadei, the fabled queen of Chitrakot, whose unparalleled beauty had enticed the lustful eyes of the foes along with the kingdom of Chitrakot, and its consequences stayed afresh in the tribal minds. Followed by the deception and assassination of the king by his trusted minister, Queen Mahadei, swore that she would avenge her husband's death through her son. The son was then ten years old while the Queen was twenty. Hence, with her four truthful soldiers, she escaped into the wild forest, entered the impenetrable Bonda country and later lived among the Bondas, who worshipped her as the 'Mother'. Residing in the newfound land of the Bondas, Queen Budei observed the tribals to be kind and free as 'Mother Nature':

They were nature's children - as open, as clear, as harsh, and as exposed to nature. They did not know what falsehood was: they were as straight as the trees that grew on the mountains and as uncomplicated as they were. If you were not a friend, you were a foe. (5)

Exchanging each other's trust, the queen taught the tribals the art of combat.

Consequently, the Bonda tribe including the children as young as five took up arms to protect her. As a result, they became very skilful in the use of weapons, especially the bow and arrow. It is symbolic that when a male child is born in the community, an arrow is used to cut his umbilical cord using the sharp point of an arrow. Until today, the Bondas are feared by the outsiders, especially when they carry their weapon but "it was the fear of the guns and the gulangkhata that kept the Bondas in check" (91). The point here is that the suspicious and violent nature of the Bondas is equated to the legendary event of betrayal, which is an 'illusory thing'. By means of their legend, the tribes believed that if a trusted minister can betray, no one can be trustworthy, which is a 'false representation'. Because, although the Bondas are said to be suspicious in nature, they have ironically reposed complete faith and trust in the Dombs, who are outsiders and who do not belong to their community as it is described in this way: "It was after the Domb's coming that the Bondas became aware of the world below - a hostile world that was waiting to rob and destroy (85). According to Verrier Elwin, the Dombs are "important agent of culture-change" (21) of the Bondas, who make themselves familiar in the plains as well as on the mountains and can speak different languages. With sly mind and glib tongue, they have a way of perpetuating “...quarrel with their lies and deceit. The simple Bondas never fathomed their treachery; they trusted the outsider rather than their own blood. The Dombs knew how to talk smoothly, but the Bonda's talk was blunt, rough" (62) and that gave the advantage to control the tribe. The Domb is the Bonda's 'eyes' and 'ears' as the Bondas cannot communicate with the gulangbabus (government officials) directly except through the Dombs who knows his language.

The Dombs had told the Bondas that once their names were written in the khata, the government could take their lands away, force them to work as gotis, even hang them...The Bondas had been told by the Dombs that just as the gods, dumas and witches had to be placated with offerings of meat, eggs and liquor, so did the babus have to be humoured with gifts. (90-91)

Not only the Domb could easily interpret the conversation in any way as he pleases for his own gains but there was also great unity among the Dombs; together, they conspired to give the Bonda a bad name as mentioned: "The Bonda inspired so much terror among the plainsmen that no one dared to come to his country. The Dombs enjoyed a 
monopoly” (95). Through her narrative, Ray exposes the treachery of the Dombs as the prime reason for the cultural disintegration of Bondas. Because of the Bonda's absolute dependence in their day-to-day existence on the Dombs, who "acted as interpreter and mediator," their downfall becomes inevitable and also stands in opposition to their mythical belief of distrust toward the outsiders. The narrative thus points out to the ironical contradiction in the behaviour of the tribe. Their representation as 'suspicious' in nature loses meaning when they fail to suspect the Dombs, who becomes responsible in corrupting the simple minds of Bondas, and thus the readers are disillusioned by the Bonda myths and beliefs.

Ray connects the distrustful nature of the tribes to another myth, and their extraordinary system of marriage can be a reproduction of the legendary event of a child and a mother (as a caregiver) as represented through the allusion of Queen Mahadei and her son. After crossing the age of fourteen, a Bonda man finds it challenging to find himself a wife; no woman would select him for a husband. An older man cannot be trusted. The Bondas have yet another myth behind this perception. A long time ago, a father-in-law pretending to be Bonda God Mahapru cheated his son's wife into sleeping with him. Alluding to this incestuous event, no Bonda woman trusts a matured Bonda man. The woman perceives that the child is frail in mind and body but as soon as he turns into a man, he changes his behaviour and mentality. Hence, he cannot be considered reliable. Consequently, a man is considered too old and well past marriageable age. But in reality, due to the strange Bonda marriage system, since the groom is young, hardly ten year old, naïve and helpless, it is a common practice to see the woman's father-in-law or brother-in-law involved in an affair with the newly arrived bride. This is the reason, why the Bonda man remains suspicious starting from his first helpless wedding night. However, if someone tells him that his spouse is having an incestuous affair, he may silently get angry but remain silent because a typical Bonda man does not trust his ears. On the contrary, if he sees his wife with his father or brother with his naked eyes, he will not hesitate to kill them with his weapon. The nature to suspect and the inability to control rage has often provoked him to murder.

As evident in many tribal communities, the culture of sapung (alcohol) consumption is deeply ingrained in the Bondas. The causal effects of heavy intoxication, especially by the Bonda men are traditionally attributed to a legend concerning the nourishing nature of salap trees, which is a representation of the Bonda men's pride and way of everyday life. Because of the intoxicating element in the salap juice, the salap trees have been the cause of murder, rioting incarceration, imprisonment, and hanging. The continuation of the inherent drinking culture escalates the death tolls of the Bonda population, which is already diminishing. As essential as sapung is for the tribesmen, the sahukars (moneylenders) are a pivotal lifeline in the tribal existence. They are necessary in the Bonda's life because they give him money when he is in need. The Bonda's expensive ceremonies, the ornaments he has to buy to win a selani, and the bride-price, which he mostly cannot afford make him pledge his land, his fruit trees and lands, sometimes his wife and children to the tyrannical sahukar. Thus they are entangled in the problematic web of existence because of their strong affinity to their customs that enslave them. 


\section{Bonda Marriage System and Gender Issues}

In the peculiar tribal marriage system, the woman believes that she would have somebody to look after her, especially in her old age. However, it is not materialized in the practical sense of the community. The contrasting characters of Bagha Bindhu, who is ripened with pride on his return from the jail, and Budei Toki, who had to toil and maintain her chastity for the former, especially in his absence for fourteen years is an evidence for the futility of a Bonduni's aspiration. Finally, because she was growing old, Budei had to accept longsi (divorce), which causes her an unprecedented emotional trauma and suffering. The passage of time has made Budei Toki a dokri (old) and all the labour and pains she has endured in his absence is wasted. Returning from the prison, Bagha Bindhu ogled their daughter-in-law, who was carrying a baby and on top of that, he brings home a chhotli (junior wife) and Budei is disheartened. Annoyed by the situation she screams, “...just because I am old, do you think I have no rights?” (181), but ironically she could neither protest nor assert it 'as a matter of her right' because tribal laws do not have provisions for women's rights. When Bagha Bindhu easily gives Budei Toki a longsi (divorce) and as interpreted by the systematic tribal law, she has to surrender the home that she has built and has to leave without any objection. She leaves her dia (house) and everything that she had worked for turns into an uncertain future. Paradoxically, her father along with the male members of her family arrive making a great tumult. But, making no move to take back Budei Toki, they just kill and feast on Bagha Bindhu's domestic animals, which show that justice is not there for Budei Toki, who is the representation of the tribal women's predicament in the patriarchal system. Ray states that "Youth is the Bonduni's sole asset; when it is gone she is welcome nowhere. No one needs her - not husband, father, brother or son" (183). The reason for a Bonduni to marry a young Bonda to help secure her old age is just a hypocritical perception whereby no dokri had been well looked after in her old age by her husband. A Bonduni's youth and hard labour become an asset as well as a target for the tribal men to exploit. Ultimately, this marital custom is a self-imposed cultural imprisonment in Bondunis' existence.

Budei's life replicates the problem of a tribal woman marrying a young husband as demanded by the culture. The common belief that the Bonda woman would have someone to look after her when she becomes old proves to be an illusion and irony, taking into account the case of Budei. Hence, the event aligns with Barthes' concept of myth as 'illusionary' in nature and application. Though appearing matured and tolerant with the community's system, Budei is victimized by her tribal customs and laws. She is doubly subjugated, as she does not qualify for the government's provision for the aged and widowed woman because Bagha Bindhu is alive. The myth of the marriage system culturally enslaves the women who are doubly subjugated. Ever since her marriage to Bagha Bindhu, Budei Toki had to toil in the fields and later she had to suffer after the divorce. Culture gives ample space for the tribal men to justify their socially unjust actions while women suffer silently to protect the culture. Hence, the complex marriage tradition leads to cultural enslavement and isolation for the Bondunis.

The author's account of the Bonda marriage culture shows that this practice has a drawback for the female. Even though it is often supposed that the tribal woman enjoys more freedom than women of the plains, the Bonduni does not enjoy the same privileges as tribal men. The sindbore, a stone platform where the village council meet, is an 
exclusively male domain without any representation for women. Tribal women are always preoccupied with too many tasks to contest the male domain in the land of the Bondas. Stereotyping of gender is prominently visible when the jail returnees among the Bonda men start to wear dhotis without any objection from the members of the community. However, when a woman wants to wear sari by relinquishing the practice of ringa, a string of beads, the assembly of menfolk turn it down for the fear of Goddess Sita Takrani's curse, which is believed to harmfully affect the Bonda community. It is evident that no woman occupies any significant position in the social order of the tribal community. In this way, almost all tribal laws and conventions are applied mainly on Bonda women, whereas the Bonda men go scot-free. The system is bound by peculiar laws where almost all the responsibilities befall upon women and there exists a disparity of gender. Tribal women struggle single-handedly to maintain land and possession and they endure hardships in their everyday existence while men enjoy drinking sapung. With an exception to decision making, ploughing the fields, and cutting tall trees, men have fewer roles to play in the community. Hence, the predicament of the tribal women is presented through the system of marriage bound by the chain of myths.

\section{Intrusion of Mainstream Social Forces and the Resultant Tension}

The Bondas, residing in the wild mountains are secluded from the outside world by the runukbore, the wall that marks their territory whereas the Bondas who have left their ancestral homeland for the plains have embraced the ways of the outside civilization. Consequently, they have started to hybridize themselves with the cultures of the people of the plains. Because of this growing trend, the Bondas of the hills (Upper Bondas) have no respect for the Bondas of the plains (Lower Bondas) as they have started to adjust socially and culturally with the ways of the outside world after forfeiting the tribal culture and beliefs. Against the myth of shaving their heads, the Bondunis who have migrated to plains have started to keep their hair long and no disaster had befallen on them. It shows that the tribals have falsified mythical beliefs which distort their perceptions.

Imprisoned by their inherent cultural practices, life continues to be hard for the Upper Bondas and their numbers decrease because of constant feuds and tensions not only amongst themselves but also with the Lower Bondas. The socio-ethnic tension between the two Bonda factions is created because of the differences of desertion of one's land and assimilation with the outside world. Consequently, the Lower Bondas hated the Upper Bondas for being murderers, while the Dombs continue to trigger the tension between the two Bonda groups, known for a violent instinct upon the slight interference, "A Bonda would not hesitate to kill a man, but interfering with a custom was another matter!" (44). There are several occasions and incidences when the two groups clashed. Imprisoned by their inherent cultural practices, life continues to be hard for the Upper Bondas and their numbers decreased because of constant bloodshed amongst themselves and with the Lower Bondas. As a result, the survival of the tribe with their intact cultural identity is in question. On the contrary, the Lower Bondas who have surrendered their inherent cultural traits to the ways of the outside world have not only increased in number but their living condition has also improved with the passage of time. Hence, the Upper Bondas are trapped in their own small world of ancient cults and traditions and they have compromised their existence for the sake of identity, which 
endangers their survival. On the other hand, the increase in the population of the Lower Bondas with their distorted identity proves that it is impossible for a tribal to exist with an intact identity as he treads the ways of modernity.

Verrier Elwin had envisioned that integration is inevitable for the Bondas but it should happen in a gradual way. When people from the outside world such as the reformers and missionaries entered into the Bonda country, the Bondas became more suspicious; they feared that they would end the Bonda civilization while attempting to bring a change. It is hard for the Bondas to understand why the Hindus drink milk but abstain from the intake of beef; to him drinking cow's milk is worse than drinking their blood. Ideologies and perceptions differed. Furthermore, the tribals were angered when the Christian missionaries called their Mahaprabhu a false god. They were in dilemma when the Muslim visitors told not to eat pork and to have only one God but not their Mahaprabhu. He feels that if he does not offer biru (ritual sacrifice offered to a deity) to all the gods, they would curse him. It is described in the book in this way: "As every visitor to the Bonda country had attempted to change him, the Bonda was convinced of a conspiracy to destroy the tribe. This made him cling all the more fiercely to his beliefs: all doors and windows were shut against the winds of civilization” (91).

Despite the rigid tribal culture and customs, with the advent of modernity, the tribes are forced to accept change. There are two instances when the Bonda makes contact with the outside world, and ironically, these are the instances where he manages some semblance of education. One instance is when he goes to jail upon committing murder and the other is when he goes to work in the tea gardens of Assam. In jail, a Bonda meets hardened criminals and learns not only their language but he also learns to count, a few letters of the alphabet and Oriya, with a little bit of Hindi and English. Some return with umbrellas, use it instead of the tarla (local shade) and brandish a torch even when the battery finishes. Moreover, he learns to "wear a lungi round his legs," "a shirt over his chest," "smoke biris instead of dhungias," and "drink hot sha (tea)." He learns to shake hands city fashion and "These were the pioneers, the fore-runners; they knew the world!" (120). A similar case is with one who returns from the tea gardens of Assam. After returning from Assam, Sukra Madra said, "The towns-people are always fighting over different gods - killing each other. Now the same thing will happen to us!” (120) He did not realize that the Bondas themselves are introducing the change besides the change the missionaries are trying to bring to the Bonda country. As the old inherent Bonda ways of life are being blended with the new culture, the primal identity gets diluted.

\section{Impacts of BDA on Bonda Culture}

Since 1976, with the establishment of the Bonda Development Agency (BDA) by the government, efforts have been made to bring the Bondas of the mountains into the mainstream by providing education, better sanitation, and drinking water facilities. Nevertheless, Jitendra, in an article on Down to Earth, claims, "Though the BDA has been in existence for over 40 years, the developmental activities have hardly touched their deprived lives" (para. 3) which echoes the events in the text. The corrupt officials placed in the Bondaland neglected their responsibilities and failed to bring improvement in the lives of the tribals. Instigated by the Dombs, with the pretext of fear for the aboriginal tribe, they hardly visited the tribal land. However, they received their salaries 
and grants on a monthly basis. The sarkar (government) failed in civilizing the savage tribe though huge investments have been made to bring a change in their lives. A social activist, Damburu Sisa, the first Upper Bonda to be elected into the state legislature in 2014, believes that mainstreaming the Bonda is crucial for the entire group's survival. Representing the tribe, he voices out, "Our cultural identity, especially our unique Remo dialect, must be preserved. At the same time, with increased awareness, the customs and superstitions, harming our people will slowly be eradicated” (qtd. in Ancient Odisha tribe Faces Extinction, para. 3).

With a tone of concern, Jitendra further reports, “Till a few years ago, spotting a member of this elusive tribe was rare. Nevertheless, now they can be seen not only in other districts of Odisha, but also in neighbouring states such as Andhra Pradesh,” and the present reality is that Bondas have started to cross the runukbore as "interactions with the outside world have also come to an expanse" (para. 3). Earlier, only a few Bonda men migrated to nearby towns and tea gardens of Assam to earn a livelihood, but now even Bonda women are reported to have started abandoning their ancestral land. Since the arrival of the tribal welfare schemes through the Bonda Development Agency (BDA) in the 1970s, the tribals have been introduced the ways of the outside world in the form of dress, agriculture, and road transport systems but with less significant impacts on the improvement of their lives. Although the tribals were reluctant to accept the new ways of life in the beginning, slowly they were assimilating themselves to change by shedding their primal customs and mode of life.

It was hypothesized that the Bondas, one of the most primitive tribes dwelling in the isolated mountains of Odisha untouched by modern civilization, was not without problems. The current study confirms that the inherent flaws within their cultural practices, belief systems, and laws, which were presumed to be the root cause of their conflicts, threaten their ultimate existence. The claim further validates that the tribe in the mountains (Upper Bondas) are enslaved by the chains of myths and rigid customs. The tribe exists not only in a constant fear of death but their numbers are also decreasing because of constant feuds and killings. Furthermore, the government's intrusion into the tribal world with development plans instead of proposing a solution to improve the tribal lives rather increases the socio-ethnic tension with their veiled politics resulting in disillusionment and dilution of the tribal identities. The hypothesis, through the discussion and critical analysis of the primary text and secondary sources undoubtedly proves with evidence that the Bondas are in the dilemma of an intersubjective position of existence and identity because of the internal problems and the outside world's intrusion. With the door opened to the outside world, the tribe cannot exist with the intact tribal identity but they will have to adapt themselves to the ways of the outside world. It is impossible for the Bonda tribes to survive and exist if they do not give up the rigid cultural practices bound by illusionary myths and beliefs.

\section{Conclusion}

In India, the tribal communities have developed their cultural identity, traditional belief systems, and economy in close proximity to the natural landscape. Their everyday life is governed by unique cultural norms and belief systems. Nevertheless, after their exposure to modernization, the factors sustaining their identity and existence shifted from myths, legends, land and natural resources to the forces of outside influence. Ray, 
in her The Primal Land, has explored the tensions in the contact between tribal and supposedly-civilized outside societies and the loopholes in the governmental plans though it is meant for the betterment of the Bonda tribe.Using techniques such as myths, legends, and stories of the origin of Bonda tribe and its past glory, the novel not only records the tribal past and narrates their glory but it also tells what had happened to them and what had been lost. The novelist delineates how an uninvited intrusion from the outside world complicates the tribe's position, which leads to socio-ethnic tensions in the end. The novel projects the postcolonial problems of the tribe by capturing the domination of hegemonic culture and tribal resistance through different voices. The fundamental question of contestation lays in their existence whether the tribe should exist as Bondas with primal identity or to change and adapt themselves to the influences of the mainstream society. It was observed that their situation was complicated by the inherent cultural complexities that caused internal factions, which further questioned their existence in the wake of modernity.

The critical examination of the selected text with the use of secondary materials proves that the Bondas cannot exist with their inherent identity owing to the influences from the outside world. The finding is that the tribal existence is threatened internally because of the rigid cultural practices such as the marriage system, which doubly subjugates tribal women and the culture of bride-price payment in kind further pushes the Bonda into debt. Moreover, the study has confirmed that the Bonda men's complete dependence on the salap juice leads them to incessant rage, misunderstanding, murders and imprisonment, ultimately causing more killings and a drastic decrease in their number. The Census of India 2011, records the population of the Bonda community as twelve thousand two hundred and thirty one wherein the females outnumbered the males, which shows that the Bonda men's population is not growing either due to imprisonment or incessant death tolls. On the other hand, the government'seffort to mainstream the tribe with developmental projects and programmes, rather than bringing significant improvement to their lives, disintegrates and dilutes the Bonda culture, resulting in further factions among the Bondas, which complicates their position. It has been confirmed that the Bonda tribe cannot exist with their tribal identity intact, but to survive, they will have to change and compromise. Thus the study has decoded the difficulties of the Bonda tribe and has found out that their existence cannot be ensured without the loss of the primal identity.

\section{Works Cited}

Anderson, Gregory D.S., and K. David Harrison. The Munda Languages. Edited by

Gregory D.S. Anderson, Routledge, 2014. books.google.bt/books?hl=en\&lr=\&id=6GzxBwAAQBAJ\&oi=fnd\&pg=PP1\&ot s=7IjY8hxkzJ\&sig=9A-Lq5qN4ehd8pxi-MAQ-

RNKUII\&redir_esc $=\mathrm{y} \# \mathrm{v}=$ onepage \&q\&f=false

Elwin, Verrier. Bondo Highlander. Oxford UP, 1950.

Government of India. Census of India. Office of the Registrar General \& Census

Commissioner, India, 19 February 2021,censusindia.gov.in/2011common/censusdata2011.html 
Jitendra. "The First Wave of African Migrants Leaving Malkangiri, Odisha-Their Ancestral Region-In Search Of Livelihood.” DownToEarth, 10 February 2021, www.downtoearth.org.in/news/forests/the-next-wave-59731.

Leak, Andrew N. Barthes, Mythologies. Grant and Cutler, 1994. Lecture. https://www.uv.es/ fores/programa/barthes_mythologies.html

Nanda, Bikram Nandha. Contours of Continuity and Change: The Story of the Bonda Highlanders. SAGE Publications Pvt. Limited, 1994.

Pati, Rabindra Nath, and Jagannath Dash. Tribal and Indigenous People of India: Problems and Prospects. A.P.H. Publishing Corporation, 2002.

Ralte, Rualzakhumi. Ethnographic Narrative: Representing the Tribal in the Selected Works of Verrier Elwin, GopinathMohanty, Pratibha Ray and Mahasweta Devi. Doctoral Dissertation, Mizoram University, 2012. mzuir.inflibnet.ac.in/bitstream/123456789/255/1/Rualzakhumi\%20(English)\%20 -\%202012.pdf

Ray, Prathiba. The Primal Land. Translated by Bikram K. Das. Orient Longman, 1993.

Sengupta, Nirmal. "Tribal India: History, Politics, Polemics.” Economic and Political Weekly, vol. 21, no. 4, Jan. 1986, pp. 161-163, JSTOR, www.jstor.org/stable/4375252.

Sharma, Suresh. Tribal Identity and the Modern World. Sage Publications, 1994. 